\title{
Effect of the Inlet Gas Humidification on PEMFC Behavior and Current Density Distribution
}

\author{
Daniel. G. Sanchez ${ }^{\mathrm{a}}$, Tiziana Ruiu ${ }^{\mathrm{a}}$, Indro Biswas ${ }^{\mathrm{a}}$, K. Andreas Friedrich ${ }^{\mathrm{a}}$, Juan Sanchez- \\ Monreal $^{\mathrm{b}}$, Marcos Vera ${ }^{\mathrm{b}}$. \\ ${ }^{a}$ Deutsches Zentrum für Luft und Raumfahrt (DLR), Institut für Technische \\ Thermodynamik, 70569 Stuttgart, Germany \\ ${ }^{\mathrm{b}}$ Dept. de Ingeniería Térmica y de Fluidos, Universidad Carlos III de Madrid, 28911 \\ Leganés (Madrid), Spain
}

\begin{abstract}
Water management represents one of the main challenges in the design and operation of PEMFCs. The influence of inlet gas humidification on cell performance is analyzed using in-situ diagnostic tools, such as cyclic voltammetry and segmented cell current density measurements, supported by post-mortem ex-situ investigations. Particular attention is paid to the effect of low humidity conditions in both cathode and anode, under which the cell is observed to suffer severe voltage decline. A simple onedimensional water balance model is proposed to contribute to the understanding of the various operation regimes observed in PEMFCs under medium-to-low humidification conditions.
\end{abstract}

\section{Introduction}

Recently significant progress has been made toward meeting the challenging cost and performance targets required for the use of polymer electrolyte membrane fuel cells (PEMFCs) in automotive applications. The state-of-the-art of polymer electrolyte membrane fuel cell technology is based on perfluorosulfonic acid (PFSA) polymer membranes operating at a typical temperature of $80^{\circ} \mathrm{C}$. Since the ionic conductivity of PFSA membranes depends on the water content of the membrane, water management is one of the most important issues for successful operation, high performance and good durability of PEMFCs. Excess inlet gas humidification as well as condensation processes within a PEMFC are likely to produce an accumulation of liquid water in the porous electrodes and gas diffusion media (effect known as flooding), thus decreasing the electrochemical activity and performance. On the other hand, an insufficient level of gas humidification lowers the ionic conductivity of the membrane and results in a performance reduction too.

Numerous studies have investigated the operation of PEMFC under dry conditions to simplify operation. Early work to demonstrate stable performance for PEMFC using dry or slightly humidified gases has been reported by Büchi et al (1). Strategies for operating polymer electrolyte fuel cells include also the reduction of humidification of both reactant gases (2-4) or the dry operation of cathode (5-7) or anode sides (8).

This work investigates the stability of cell performance operating under different humidity levels, showing the close relation between stability and homogeneity in the 
current density distributions. A simple model is also included to describe the observed phenomenology.

\section{Experimental details}

To study the cell response at different humidification levels a single cell with an electrode area of $142 \mathrm{~cm}^{2}$ was used. The cell was developed in-house to be used in stack testing at the German Aerospace Center (DLR). The test bench is equipped with programmable logic controllers (PLCs) and commercial electronic loads. It allows automatic control of the operating cell conditions, such as cell pressure, cell temperature, gas flow rates, and humidity of reactants. The relative humidity of the inlet gases is controlled by mass evaporator mixers and the temperature is kept constant at $80{ }^{\circ} \mathrm{C}$ using a thermostat. The load may be operated in galvanostatic (i.e. constant current) or potentiostatic (i.e. constant voltage) modes.

The operating conditions are summarized in Table I.

TABLE I. Experimental conditions.

\begin{tabular}{ll}
\hline Cell Temperature & $80^{\circ} \mathrm{C}$ \\
Pressure & $1.5 \mathrm{bar}$ \\
Current & $100 \mathrm{~A}$ \\
Gas Flows & Anode: $840 \mathrm{ml} \mathrm{min}^{-1}$ \\
& Cathode: $3320 \mathrm{ml} \mathrm{min}^{-1}$ \\
Relative humidity & Varying \\
Flowfield (see Fig. 1): & Counter Flow \\
& Segment Nr. \\
Anode Inlet & $\mathrm{A} 1, \mathrm{~B} 1$, and C1 \\
Anode Outlet & $\mathrm{G} 10, \mathrm{H} 10$, and I10 \\
Cathode Inlet & $\mathrm{G} 1, \mathrm{H} 1$, and I1 \\
Cathode Outlet & $\mathrm{A} 10, \mathrm{~B} 10$, and C10 \\
\hline
\end{tabular}

The membrane electrode assembly (MEA) used in the present work consists of a commercial $\mathrm{Nafion}^{(} \mathrm{XL}$ membrane, with an anode and cathode platinum loading of 0.3 $\mathrm{mg}_{\mathrm{Pt}} \mathrm{cm}^{-2}$ on each side (Ion Power Inc). For the GDL, SGL Group Sigracet 25 BC was used for all measurements.

In order to visualize the effects of different relative gas humidity levels on the homogeneity of the current distribution, locally resolved current density measurements were performed.

For that purpose, a segmented bipolar plate based on printed circuit board (PCB) technology with 25 integrated temperature sensors $(9,10)$ was used as anode plate. In all the experiments presented in this work, the current density distributions are shown using relative current density, which means that the current density of each segment is divided by the current density of the total cell. This allows easy identification of homogeneous changes of current density distributions at different conditions.

Cyclic voltammetry measurements were performed using an electrochemical station (Zahner). 
Ex-situ photoemission studies were performed with a Thermo Scientific ESCALAB250 system with a base pressure of $4 \cdot 10^{-10}$ mbar, using AlKa radiation. Samples were cut from selected positions and mechanically delaminated in order to access to the inner surfaces of microporous layer and catalyst layer.

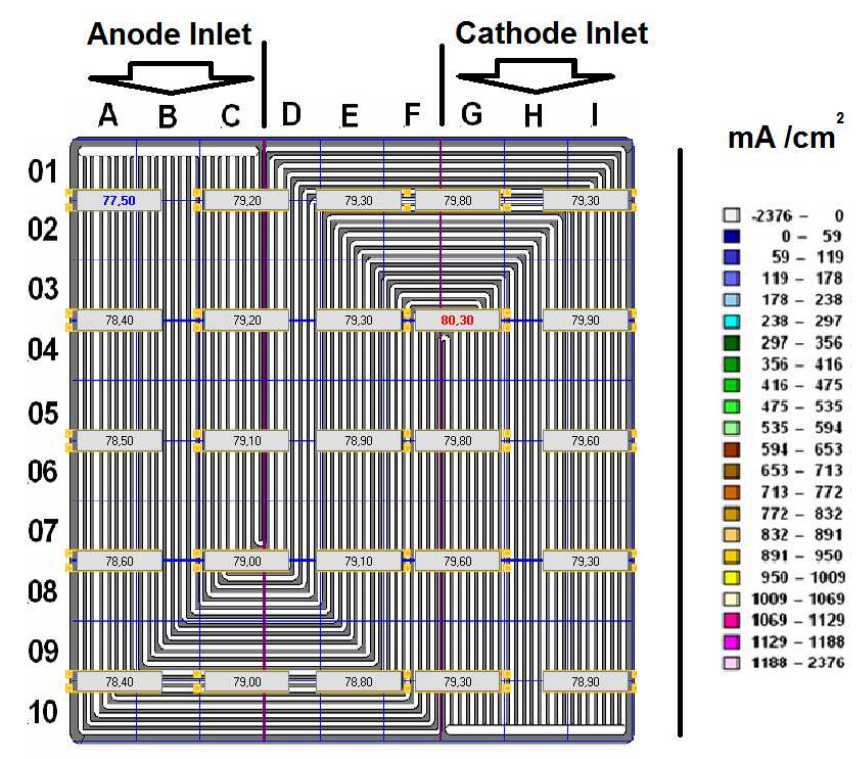

Figure 1. Multiserpentine segmented cell design: (A) segment distributions with the location of the temperature sensors and (B) color code for current density ranges.

\section{Results and Discussion}

In order to increase the PEMFC efficiency, the reduction of the relative humidity of the input gases plays a very important role. Decreasing RH from 100\% to 50\% and $20 \%$ reduces respectively the power used for humidification to about $40 \%$ and $14 \%$ of that corresponding to fully humidified gases. Note that in this experiment, the power used to reach $100 \%$ RH on the cathode stream is about $50 \mathrm{~W}$.

In this work, an overview about the influence of the relative humidity on the cell stability and current densities distributions is presented. Most of the experiments were performed under the conditions shown in Table I.

It has been observed that values of 50\% RH did not reduce the performance compared to $100 \% \mathrm{RH}$ and highly stable and homogeneous current density is observed. This result can be observed in Figure 2. For this reason, humidification reference conditions were defined at $50 \% \mathrm{RH}$ on both sides.

In order to reduce influences between consecutive experiments, and assure the same initial cell conditions before measuring at different RH levels, the cell was returned to the reference conditions $(50 \% \mathrm{RH})$ after each experiment. 


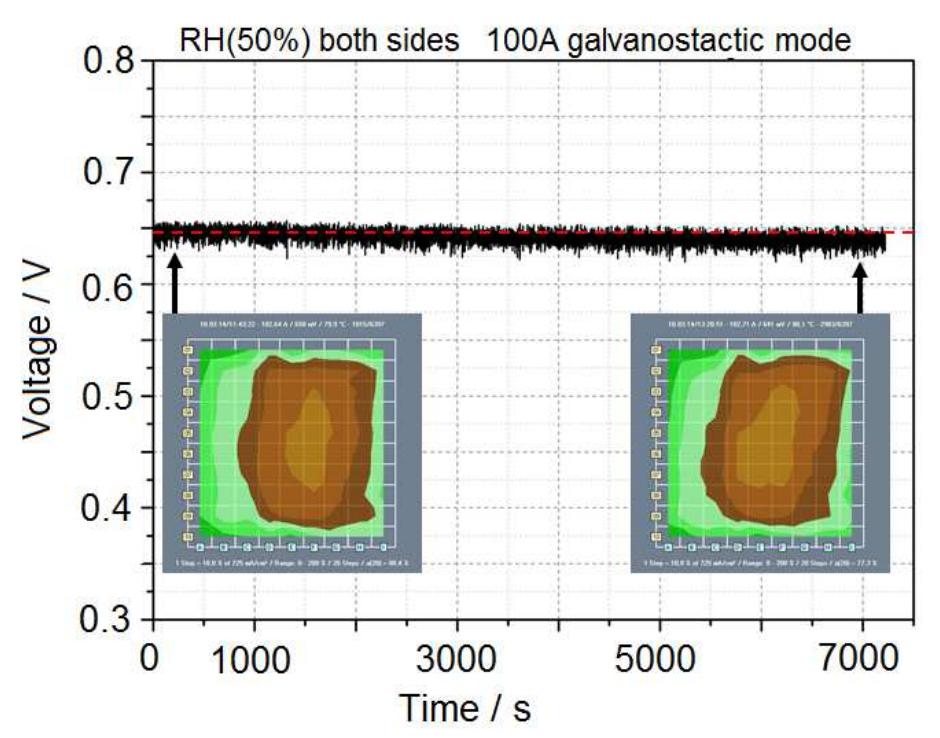

Figure 2. Cell response at relative humidity level of $50 \%$ on both sides, chosen as RH reference conditions; measured under conditions reported in Table I.

To study the influence of reduced relative humidity from the reference level, RH was reduced by $30 \%$ first on anode, then on cathode. Figure 3 shows the voltage response and current density distributions, when the RH reduction was performed.

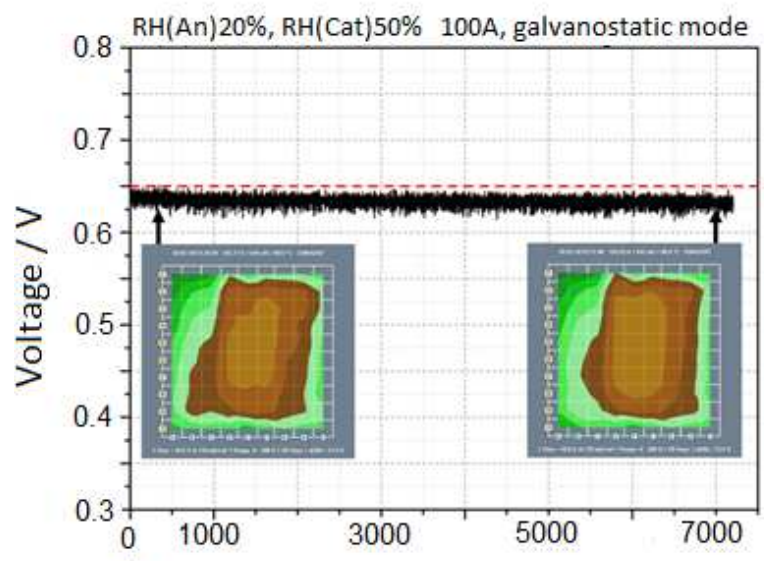

a)

Time /s

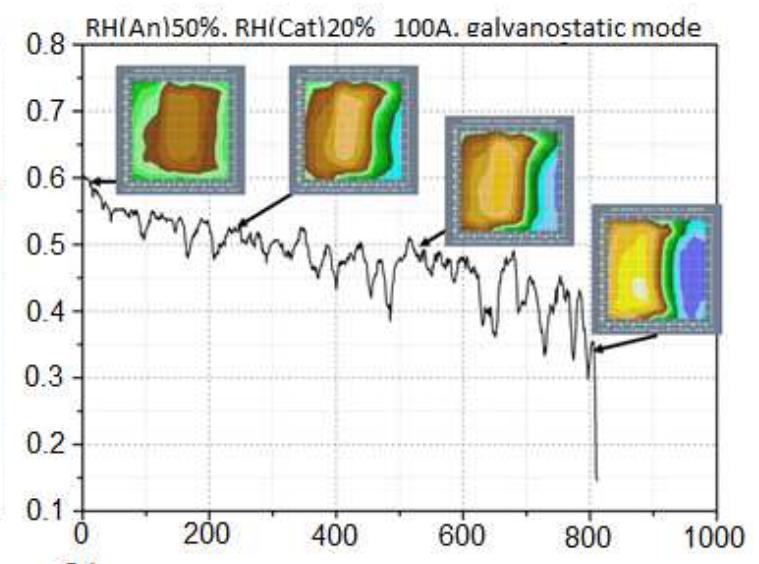

b)

Figure 3. Effect on cell response of $30 \% \mathrm{RH}$ reduction from reference conditions on a) anode side, RH (An): $20 \%$ and RH (Cat): $50 \%$, and b) cathode side, RH (An): $50 \%$ and RH (Cat): $20 \%$.

Figure 3 a) shows that decreasing the $\mathrm{RH}$ on the anode side does not produce any important changes in the stability and current density homogeneity. Conversely, Figure 3 b) shows that the same reduction in the RH on cathode side produces the deactivation of some MEA areas with very low current densities. As the deactivated area is increasing with time the voltage response is not stable and a drastic voltage decline occurs, as described by Sanchez and Garcia-Ybarra (4). 
As demonstrated in the experiment reported in Figure 3 (of which the purpose was to find the lowest values of humidification compatible with stable behavior), the reduction of relative humidity in the anode side did not lead to drastic loss of cell performances and stability, therefore the cell was operated with dry gas supply at the anode side. Figure 4 shows cell responses under different relative humidity values in the cathode side: a) $100 \%$, b) $70 \%$, c) $50 \%$ and d) $20 \%$.

At values of RH on cathode side between $100 \%$ and $50 \%$, a stable behavior of the cell without performance losses is observed. Further, the current density distribution is quite homogeneous and similar to the reference conditions reported in Figure 2. A negligible decrement was measured in current densities at the cathode inlet (specifically at column I, see Figure 1 for segment locations) at higher cathode humidification, Figure 4 a) and b). In contrast, Figure $4 \mathrm{~d}$ ) shows that $20 \% \mathrm{RH}$ on cathode produces an unstable behavior, accompanied by current density deactivations and drastic voltage drop. This behavior can be correlated to the observation in Figure $3 \mathrm{~b}$ ). The voltage drop shown in Figure $4 \mathrm{~d}$ ) is faster than the one in Figure $3 \mathrm{~b}$ ), which is the consequence of lower RH value at the anode.

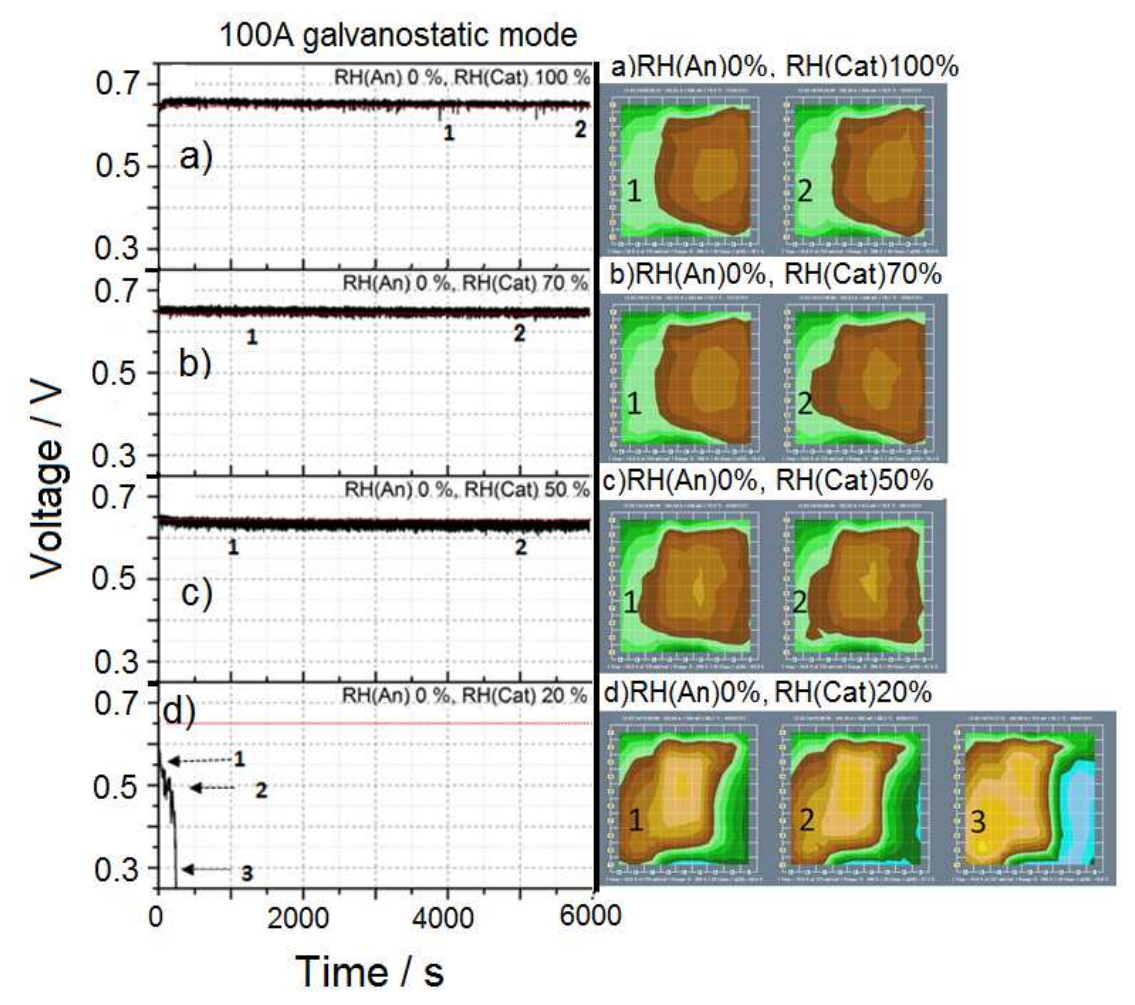

Figure 4. Transient cell performance under dry anode supply and different RH values at cathode inlet: $\mathrm{RH}$ (Cat) a) $100 \%$, b) $70 \%$, c) $50 \%$ and d) $20 \%$. The other experimental conditions are reported in Table I. The red line represents reference response at $50 \% \mathrm{RH}$ on both sides. The numbers represent the points corresponding to the relative current density distribution maps shown on the right.

The latter experiments showed the possibility to run the cell under low anode humidification, but cathode humidification levels below $20 \%$ produce high decline in cell voltage. Thus next tests were oriented to study the cell response and stability working under low cathode humidification. Several studies (2,11-13) have reported an unstable 
cell behavior working under such low cathode humidification conditions. Some of these works (12-13) describe these instabilities as oscillations, transitions from high to low response levels (corresponding to a change from the hydrated to dehydrated cell), while another work (14) anticipated a model to describe this exotic phenomenology.

Figure 5 shows the consequence of raising the humidification in the anode side, working under low cathode humidification, specifically $20 \% \mathrm{RH}$. Values of $70 \% \mathrm{RH}$ on anode, Figure 5 e), cannot counteract low cathode humidification, producing current density deactivations and consequently a drastic voltage drop, as it was observed before in Figures 3 b) and 4 d).

Figure 5 d) shows how increasing anode RH from $70 \%$ to $100 \%$ prevents the voltage drop, creating a stable state with lower voltage; this was reported before in the works (1213), as a part of the oscillatory behavior documented under low cathode humidification. The characteristic current oscillation reported in (12-13) can be observed also in Figure 5 d), points 2 and 3 . Under these conditions, the drying process in cathode side dominates the cell behavior, producing the current deactivation in areas dominated by the cathode inlet (Figure 1, columns G, H and I), as consequence of low humidification at the air supply.

Figure 5 a), b) and c) shows how raising the relative humidity at anode side can produce higher stable voltages with less current density deactivation.

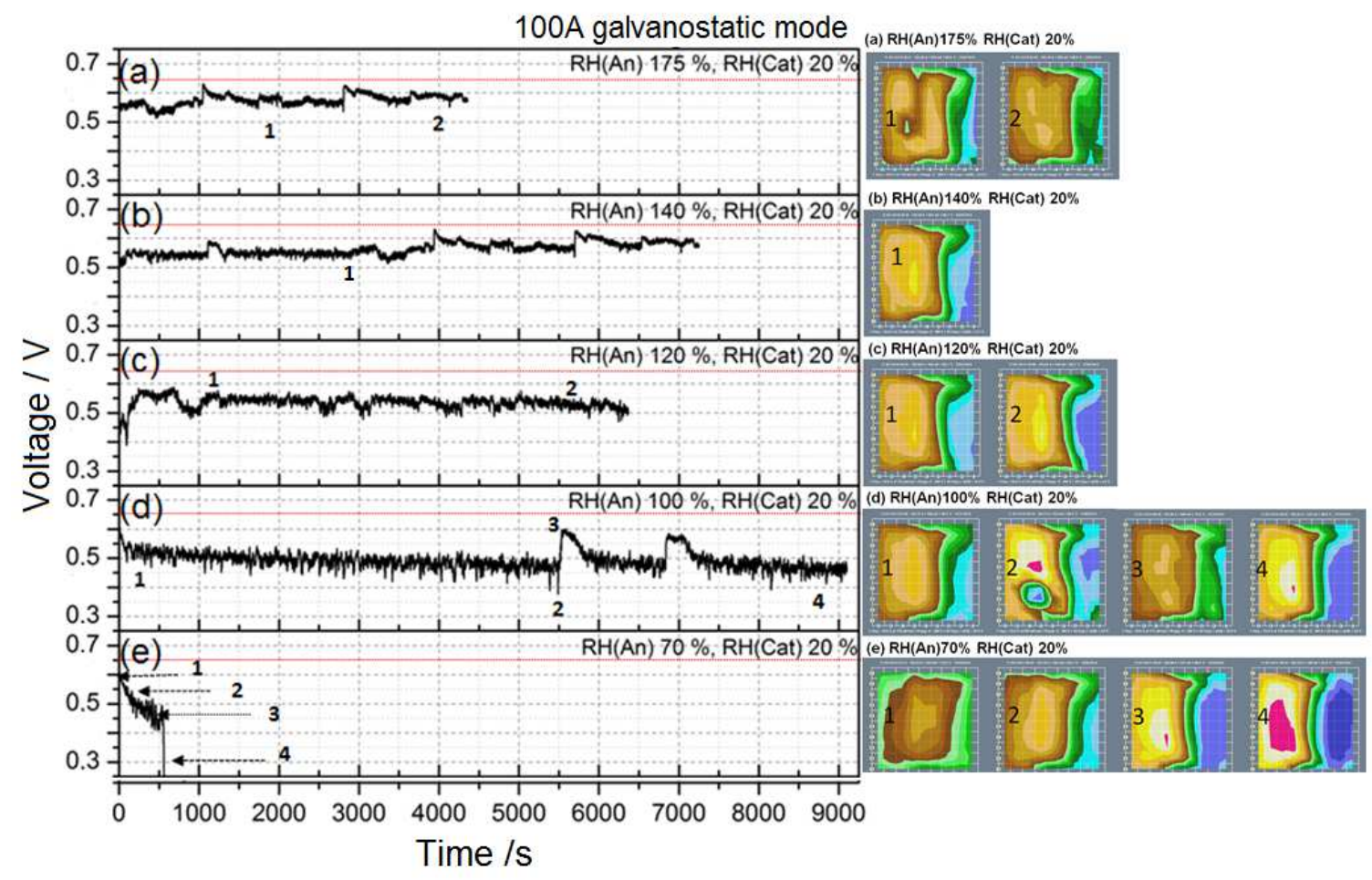

Figure 5. Cell response under different values of anode RH, with $20 \% \mathrm{RH}$ on cathode side and under experimental conditions as reported in Table I. The red line represents the reference response at $50 \% \mathrm{RH}$ on both sides. The numbers represent the points corresponding to the relative current density distribution maps shown on the right. 
Once the possibility of working under low cathode humidification (20\%, Figure 5 a) and b)) has been ascertained, the question is, if it could be possible to operate the cell under dry air supply. With this aim, different experiments were performed, increasing the $\mathrm{RH}$ in the anode side, while keeping the cathode side dry. Stable performances were obtained, with high performances at high values of anode $\mathrm{RH}$; in particular, quite good responses were observed at anode $\mathrm{RH}$ of $250 \%$.

\section{Water balance model for the membrane}

In order to gain better insight into the experimental findings, a one-dimensional across- the-membrane water balance model is proposed to contribute to the understanding of the various regimes of operation arising for different inlet humidification conditions. Taking into account the transport of water by diffusion and electro-osmotic drag, the net water flux that crosses the membrane from anode $(\mathrm{z}=0)$ to cathode $\left(\mathrm{z}=\mathrm{t}_{\mathrm{m}}\right)$ is expressed as

$$
J_{w}=-a D_{w}(\lambda) d \lambda / d z+n_{w}(\lambda) i / F
$$

where $t_{m}$ denotes the membrane thickness, $\lambda$ is the water content, $a$ is the molar density of sulfonic acid groups in the membrane, $\mathrm{D}_{\mathrm{w}}$ is the diffusion coefficient of water, $\mathrm{n}_{\mathrm{w}}$ is the electro-osmotic drag coefficient, and $\mathrm{i}$ is the cell current density. To simplify the analytical treatment of the problem, $D_{w}$ and $n_{w}$ will hereafter be assumed to be independent of $\lambda$.

Since water is neither produced nor consumed in the membrane, the water flux [1] must be divergence free. This implies that $\mathbf{J}_{\mathrm{w}}$ cannot vary across the membrane, which gives a linear distribution of the water content

$$
\mathrm{dJ}_{\mathrm{w}} / \mathrm{dz}=-\mathrm{a} \mathrm{D}_{\mathrm{w}} \mathrm{d}^{2} \lambda / \mathrm{dz}^{2}=0 \rightarrow \lambda(\mathrm{z})=\alpha \mathrm{z}+\beta, \quad \mathrm{J}_{\mathrm{w}}=-\mathrm{a} \mathrm{D}_{\mathrm{w}} \alpha+\mathrm{n}_{\mathrm{w}} \mathrm{i} / \mathrm{F}
$$

where the undetermined constants $\alpha$ and $\beta$ can be obtained by using appropriate boundary conditions at the anode and cathode interfaces. In particular, we specify the water flux at the anode (a) and cathode (c) interfaces

$$
\begin{array}{ll}
\mathrm{z}=0: & \mathrm{J}_{\mathrm{w}, \mathrm{a}}=-\mathrm{ha}\left[\lambda(0)-\lambda_{\mathrm{a}}^{*}\right] \\
\mathrm{z}=\mathrm{t}_{\mathrm{m}}: & \mathrm{J}_{\mathrm{w}, \mathrm{c}}=\mathrm{ha}\left[\lambda\left(\mathrm{t}_{\mathrm{m}}\right)-\lambda_{\mathrm{c}}^{*}\right]-\mathrm{i} /(2 \mathrm{~F})
\end{array}
$$

where $\mathrm{h}$ is a mass transport coefficient that takes into account the diffusive transport resistance of the porous layers (14) (15), and $\lambda^{*}{ }_{\mathrm{a}}$ and $\lambda_{\mathrm{c}}{ }_{\mathrm{c}}$ are the equivalent water contents of the anode and cathode gas streams, specified in terms of the respective relative humidity (14) (15) (16). Note that the last term in [3] represents water production at the cathode catalyst layer, which is incorporated into the model through the boundary condition at the cathode interface.

Substituting the expressions for $\lambda$ and $J_{\mathrm{w}}$ given in [2] into the boundary conditions [3a] and [3b] provides a system of linear equations for $\alpha$ and $\beta$, which can be solved analytically to give 


$$
\begin{aligned}
& \alpha=\left[\mathrm{ha}\left(\lambda^{*}{ }_{\mathrm{c}}-\lambda^{*}{ }_{\mathrm{a}}\right)+\mathrm{i} /(2 \mathrm{~F})+2 \mathrm{n}_{\mathrm{w}} \mathrm{i} / \mathrm{F}\right] /\left[\mathrm{a} \mathrm{D}_{\mathrm{w}}\left(2+\mathrm{t}_{\mathrm{m}} \mathrm{h} / \mathrm{D}_{\mathrm{w}}\right)\right] \\
& \beta=\left[\left(1+\mathrm{t}_{\mathrm{m}} \mathrm{h} / \mathrm{D}_{\mathrm{w}}\right) \lambda^{*}{ }_{\mathrm{a}}+\lambda^{*}{ }_{\mathrm{c}}+\mathrm{i} /(2 \mathrm{~h} \mathrm{a} \mathrm{F})-\mathrm{i} \mathrm{n}_{\mathrm{w}} \mathrm{t}_{\mathrm{m}} /\left(\mathrm{D}_{\mathrm{w}} \mathrm{a} \mathrm{F}\right)\right] /\left[2+\mathrm{t}_{\mathrm{m}} \mathrm{h} / \mathrm{D}_{\mathrm{w}}\right]
\end{aligned}
$$

and

$$
J_{w}=-\left[h a\left(\lambda^{*}{ }_{c}-\lambda^{*}{ }_{a}\right)+i /(2 F)+2 n_{w} i / F\right] /\left[2+t_{m} h / D_{w}\right]+n_{w} i / F
$$

Once the water distribution is known, the ohmic resistance of the membrane can be obtained by direct integration, $\mathrm{R}_{\mathrm{mem}}=\int[1 / \sigma(\lambda)] \mathrm{dz}$, where $\sigma(\lambda)$ represents the variation of the membrane conductivity of the membrane with the water content, which finally provides the ohmic voltage drop across the membrane $\Delta V_{\text {mem }}=i R_{m e m}$.

TABLE II. Water balance model parameters.

\begin{tabular}{llc}
\hline Diffusion coefficient of water, $\mathrm{D}_{\mathrm{w}}$ & $3.810^{-10} \mathrm{~m}^{2} / \mathrm{s}$ & $(17)$ \\
Electro-osmotic drag coefficient, $\mathrm{n}_{\mathrm{w}}$ & 1 & $(17)$ \\
Mass transport coefficient, $\mathrm{h}$ & $5.610^{-6} \mathrm{~m} / \mathrm{s}$ & $(15)$ \\
Molar density of sulfonic acid groups, a & $1970 \mathrm{~mol} / \mathrm{m}^{3}$ & $(18)$ \\
Current density, $\mathrm{i}$ & $690 \mathrm{~mA} / \mathrm{cm}^{2}$ & [assumed] \\
\hline
\end{tabular}

Model results. Preliminary results of the membrane water management model provide hints that may contribute to the understanding of the cell deactivation process. Figure 6 shows the water flux $\underline{\mathbf{J}}_{\underline{w}}$ given by Equation [5] for different relative humidity conditions, RH 50\% at both anode and cathode, RH (An): $20 \%$ and RH (Cat): 50\%, and RH (An): $50 \%$ and $\mathrm{RH}$ (Cat): $20 \%$. As observed in the experiments, the first two operating conditions are stable, while the low cathode humidification condition is unstable. It is interesting to note that the two stable conditions have negative values of the water flux, i.e., there is a net water flux from cathode to anode, whereas the water flux on the unstable condition is just the opposite, from anode to cathode. This could lead to severe membrane dehydration and to the severe voltage drops observed in the experiments.

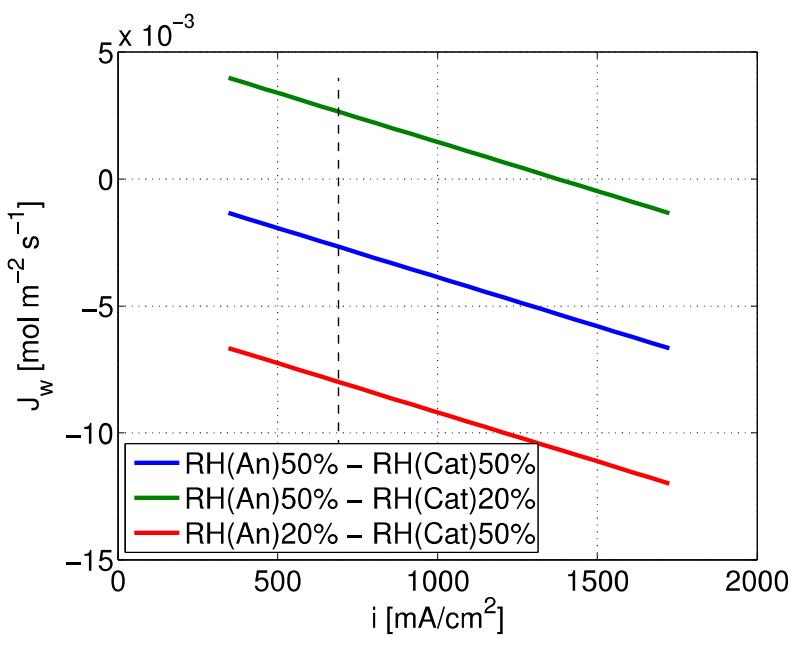

Figure 6. Variation of net water flux with cell current density for different humidification conditions at anode and cathode given by Equation [5]. Positive values of $\mathbf{J}_{\mathrm{w}}$ indicate net water fluxes from anode to cathode. The vertical dashed line shows the cell current density employed in the experiments. 
$\underline{\text { Degradation study: low cathode humidification }}$

With the aim to study the degradation process associated to work under low cathode humidification conditions, a $280 \mathrm{~h}$ experiment was performed. As extensively illustrated in the previous section, drastic voltage drops were observed at low cathode humidification levels. Hence, to exclude the degradation effect that constant current could induce at low voltages, in this experiment potentiostatic mode at $600 \mathrm{mV}$ was adopted.

Current oscillations between higher and lower values (corresponding to states characterized by a hydrated or dehydrated membrane) could interfere in degradation processes. Therefore, to reduce this influence and according to the indications described in the work (13), the cell was oriented, in order to reduce liquid water accumulation in channels. The influence of the oscillations in the degradation process will be shown in an upcoming work.

In this experiment, the gas flow rates were slightly modified from the values of Table I to $1255 \mathrm{ml} \mathrm{min}^{-1}$ for anode and $3988 \mathrm{ml} \mathrm{min}^{-1}$ for cathode, in other to avoid low stoichiometry at this voltage. The flows were maintained constant during all the experiment, to ensure a constant advection process. The humidification on the anode side was maintained constant at $100 \%$ RH, while the cathode was supplied with dry air.

Figure 7 shows the time evolution of the current under these working conditions and the current densities at two different points: a) first hours and b) end of the experiment. The difference in the relative current density mapping shows, as the degradation process is non-homogenous, that the cathode inlet columns $(\mathrm{G}, \mathrm{H}$ and $\mathrm{I})$ are the regions that present higher degradation rate. The measured degradation rate was $-84 \mathrm{~mW} / \mathrm{h}$ at $600 \mathrm{mV}$.

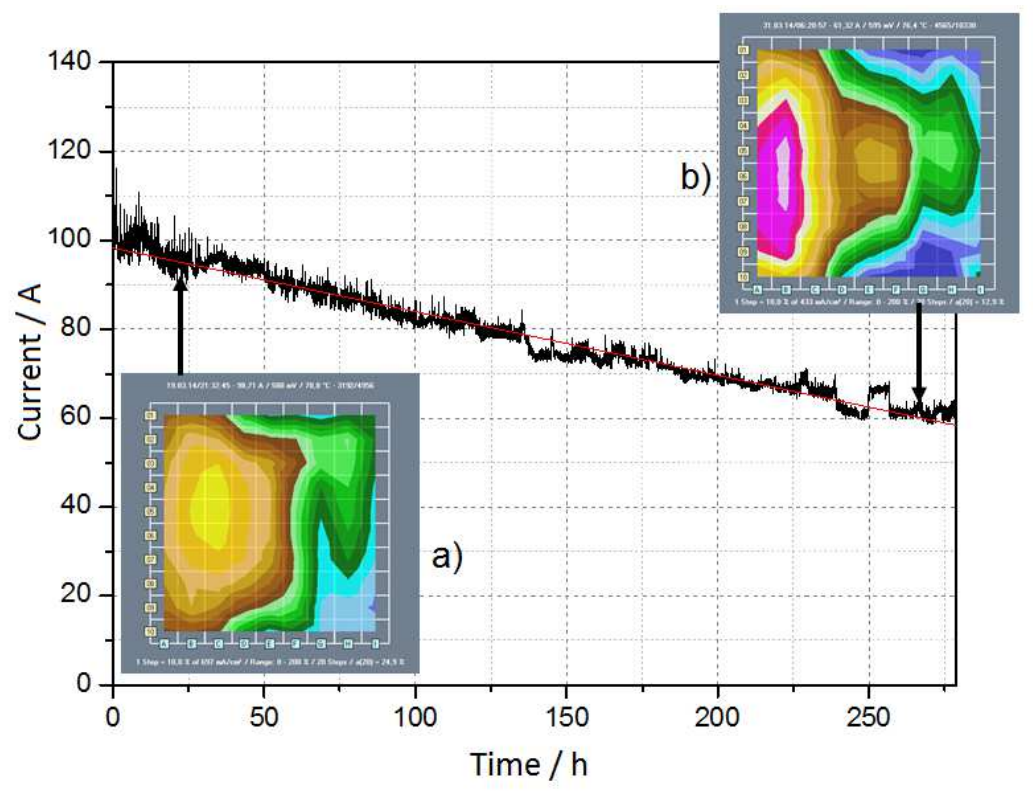

Figure 7. Current decrement under dry cathode air supply and $100 \% \mathrm{RH}$ anode stream at $600 \mathrm{mV}$, and relative current density distributions a) after few hours of operation and b) at the end of experiment. 
In-situ characterization. In order to evaluate the degradation produced by the experiment reported in Figure 7, the I-V curves and CV recorded before and at end of the test (BoT and EoT respectively) were compared. Figure 8 represents two polarization curves measured before and at end of test, under the conditions indicated in Table I at $100 \% \mathrm{RH}$, together with the corresponding relative current densities. It can be perceived that some of the segments, specifically D1, D10, E1, E10, F1, F10, G1 and G10, were irreversibly deactivated.

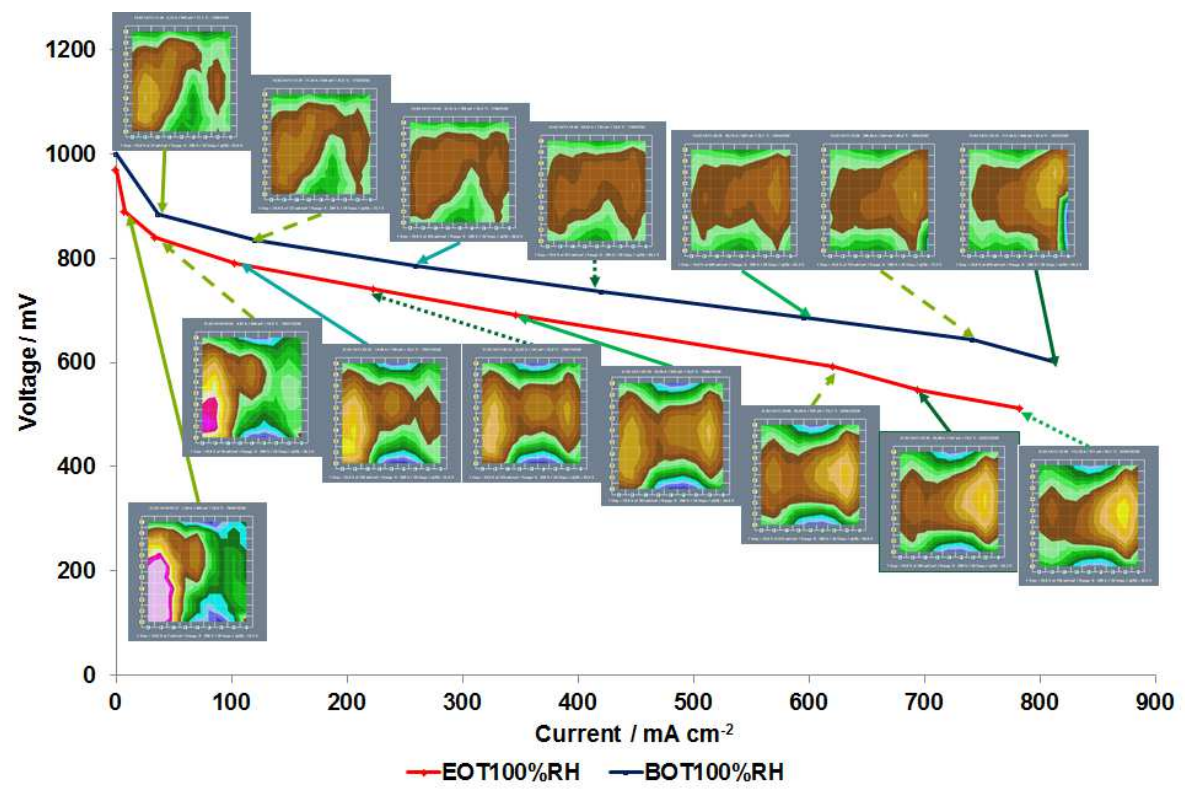

Figure 8. Comparison between polarization curves measured before of the test (blue) and at the end of the test (red) under conditions reported in Table I and 100\% RH, with the corresponding current density maps.

In order to investigate the effect of degradation on the catalyst active surface, cyclic voltammogramms (CV) measurements were performed before and after the long term experiment with dry cathode air supply, and the corresponding ECSA variations were calculated.

The CVs were recorded at ambient pressure $(1 \mathrm{bar})$ and $80^{\circ} \mathrm{C}$, using the same flow rate of $200 \mathrm{ml} \mathrm{min}^{-1}$ for both $\mathrm{H}_{2}$ and $\mathrm{N}_{2}$, and with a $100 \% \mathrm{RH}$ on both gases. The CVs were acquired at a scan rate of $20 \mathrm{mV} / \mathrm{s}$. Figure 9 displays the $\mathrm{CV}$ measured on anode and cathode before and after the $280 \mathrm{~h}$ test.

The long operation under dry cathode air supply did not influence the ECSA to a great extent, in fact the ECSA loss on the anode and on the cathode was $12.3 \%$ and $10.6 \%$ respectively. In particular, the ECSA values measured for the anode before and after the experiment were 58.6 and $51.4 \mathrm{~m}_{\mathrm{Pt}}^{2} / \mathrm{g}_{\mathrm{Pt}}$ respectively, and for the cathode 62.3 and $55.7 \mathrm{~m}_{\mathrm{Pt}}^{2} / \mathrm{g}_{\mathrm{Pt}}$ respectively.

This result would indicate that, even if the cathode was dry, it did not have necessarily a negative influence on the catalyst active surface. 

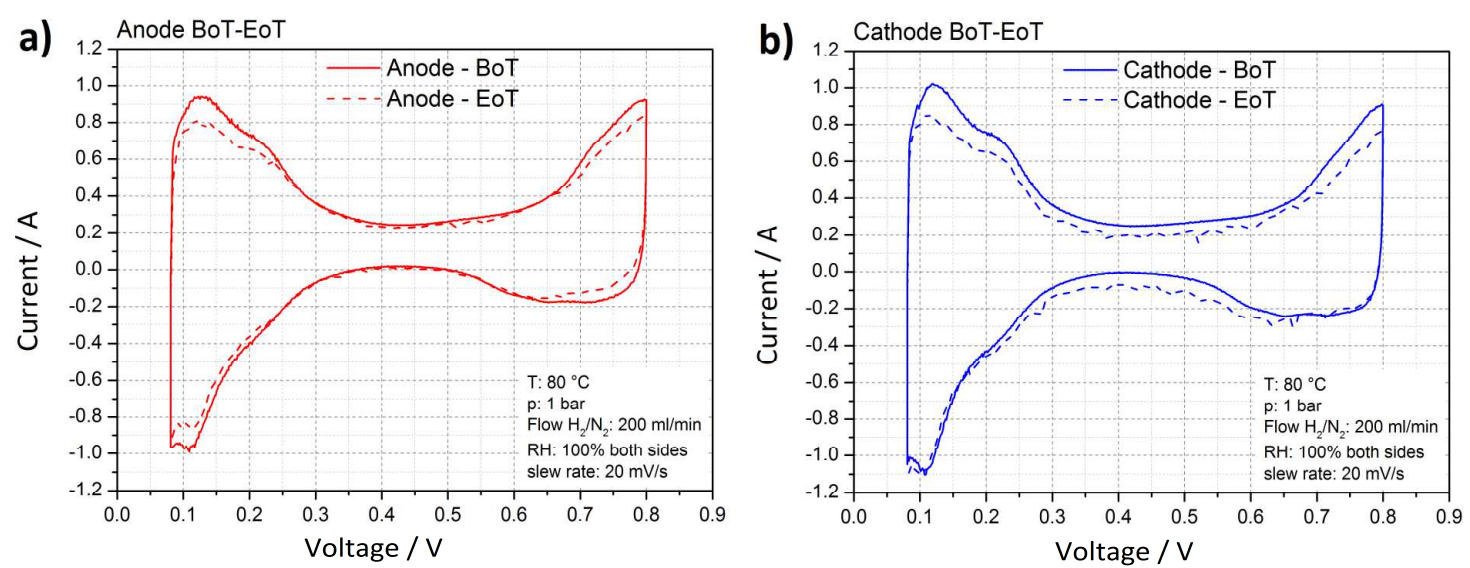

Figure 9. Comparison between CV measured on a) anode and b) cathode, before (solid lines) and at the end of the long term test (dashed lines).

Ex-situ characterization. Post-mortem analyses of cut and delaminated samples from selected areas (s. Figure. 1 for positions) were performed with X-ray photoemission spectroscopy (XPS) and compared to BoT samples. Photoemission spectroscopy gives insight into the elemental and chemical abundances of the analyzed surfaces in a nanometer range (19). Thus, the delamination of samples is necessary and allows investigating the surfaces of GDL backing, microporous layer and catalyst layer without signal overlay of, e.g. the membrane. Typical degradation phenomena that can be observed with this method are the migration of catalysts and the change in surface hydrophobicity (20-22).

At all investigated positions of the post-mortem MEA traces of platinum could be observed in all of the investigated positions of the cathode side microporous layer, as for example in position C5 (Figure 10). The dissolution and redeposition of catalysts has been reported as one of the bigger problems in fuel cell development, for it is one mechanism leading to agglomeration and reduction of the electrochemical surface area $(23,24)$. It is remarkable, that while usually catalyst metal can be observed in both cathode and anode side MPLs of aged fuel cells, this is only the case on the cathode side, here. Apparently the migration is closely linked to the strong humidity gradient between anode and cathode. The migration mechanism with dissolved platinum is supported by this observation. 


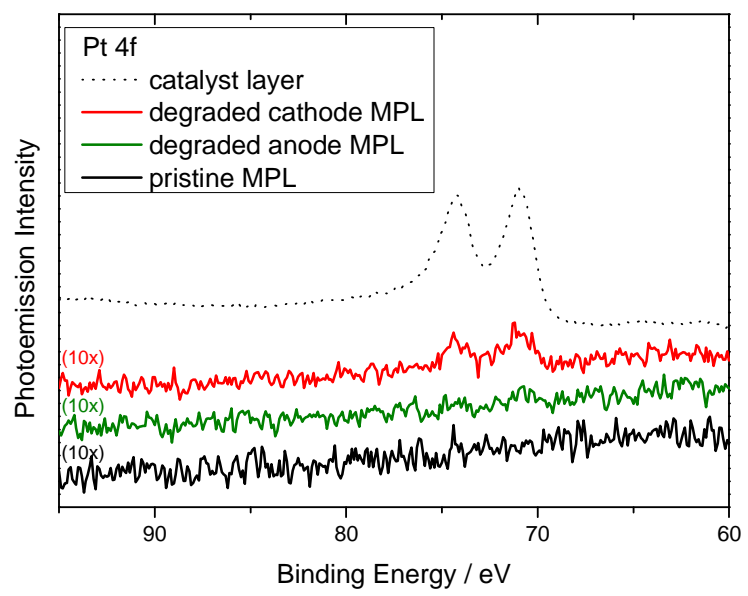

Figure 10. Platinum XPS spectra of a pristine (lower) and a degraded (middle) microporous layer at position $\mathrm{C} 05$, Traces of $\mathrm{Pt}$, migrated from the catalyst layer, can be observed at all positions of the cathode MPL, but not in the anode MPL. For comparison, the Pt4f signal of the corresponding catalyst layer is shown (upper).

The other degradation mechanism prominent in this MEA after the cathode drying test is the decomposition of PTFE, and the demixing of carbon powder or fiber and PTFE. Both effects have a direct impact on the local water management, for the mixture of these components is closely related to the delicate hydrophobicity balance (25).

Figure 11 shows the carbon 1s XPS signals of pristine and aged GDL backings. The main signal at $284 \mathrm{eV}$ is due to the graphitic carbon in the material, and the signals at higher binding energies are due to fluorinated carbon species. The pristine material shows the peak at $\sim 291 \mathrm{eV}$ for PTFE with a twofold fluorination per carbon atom. The intrinsically insulating material is well intermixed with conducting carbon. The spectra of the degraded materials, in contrast show a broad feature at $\sim 293-298 \mathrm{eV}$ that can be attributed to slightly charged PTFE. The charge builds up during the photoemission process on the weakly conducting material without a close contact to carbon. In consequence, the presence of this signal reveals the demixing of the two materials. The signal components between the two main peaks are attributed to partially defluorinated PTFE, which is well known in aged fuel cell components. The presence of signals in this energy range is parallelized with a smaller PTFE main signal at $291 \mathrm{eV}$. While two contribution of oxygen containing carbon compound upon degradation cannot be excluded in this energy range, the loss of fluorine under fuel cell operation conditions in the vicinity of catalytically active material could be proven with other methods, including the analysis of fluorine in fuel cell outlet water.

Both degradation mechanisms are able to disturb the local hydrophobicity balance, producing local hydrophobic PTFE spots and reducing the hydrophobicity in general. The consequences are the performance losses described in the first chapter.

While this degradation of hydrophobicity balance has been observed at all investigated GDL samples, there is a direct correlation of this effect in the MPL to the position within the flow field. Figure 12 shows the carbon 1s XPS spectra of the anode and cathode MPL of the aged MEA at position C5 (dotted lines), with a stable current 
density, and at position G1 (solid lines), close to the cathode gas inlet, where an irreversible deactivation was observed (s. Figure 7). The spectra at the former position resemble almost perfectly the pristine spectral shape (not shown). The latter show both PTFE degradation mechanisms described above. While no platinum depletion could be observed within the limits of these analyses, the correlation between PTFE degradation and irreversible deactivation under the given $0 \%$ RH cathode humidification shows the importance of a thorough water management for PEMFCs.

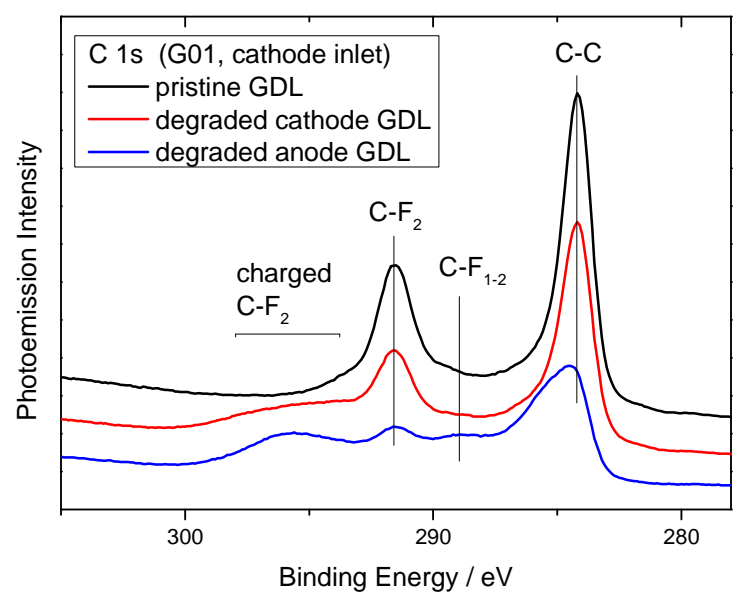

Figure 11. Carbon XPS spectra of pristine and degraded GDL backings. The initially well defined mixture of graphitic carbon fibers $(284 \mathrm{eV})$ and PTFE $(291 \mathrm{eV})$ is demixed, leading to apparently higher binding energy signals due to charged PTFE moieties (293$298 \mathrm{eV}$ ). Additionally carbon atoms with a reduced oxidation state can be observed.

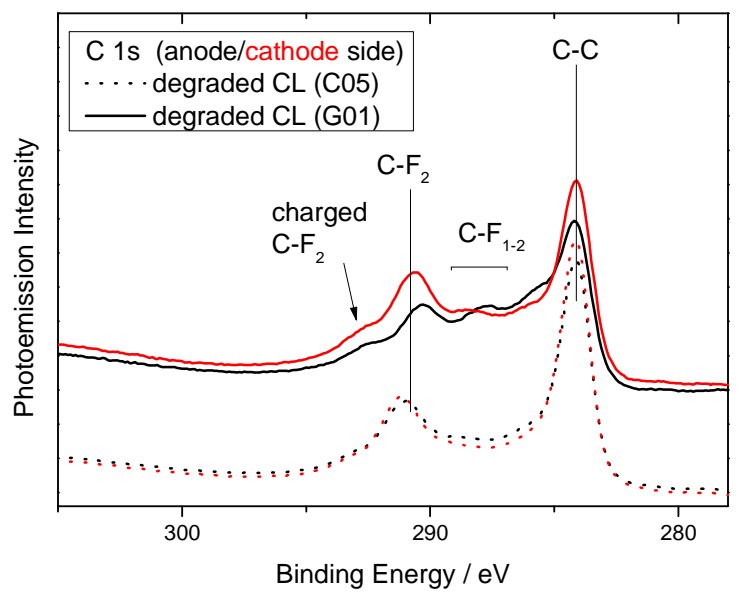

Figure 12. Carbon XPS spectra of degraded catalyst layers of the position C5 (stable current density) and G1 (irreversible deactivation). The initially well intermixed carbon and PTFE are partially decomposed (defluorinated PTFE components at $288 \mathrm{eV}$ ) and demixed (charged components, $>292 \mathrm{eV}$ ) at the latter, while the C05 spectra are almost of a pristine shape. 


\section{Conclusions}

This study shows the influence that inlet gases RH has on the cell stability. In Figure 13, colors are correlated with stability, making an intuitive mapping of the stable conditions; boundaries were defined using real experiments shown in previous sections, which are represented by squares in the diagram. Looking at this diagram, it is easy to see how the relative humidity of the cathode mainly controls the stability: in fact, $\mathrm{RH}$ values on cathode side between $50 \%$ and $20 \%$ are the key to obtain a relative stable behavior, minimizing at the same time the level of RH. Water balance model shows that net water flux from anode to cathode in the membrane, could lead to severe membrane dehydration producing the deactivation of some MEA areas and therefore causing the voltage decline observed in the experiments.

The instable behavior, occurring as consequence of low humidification at the cathode, can be compensated using very high values of RH at the anode side.

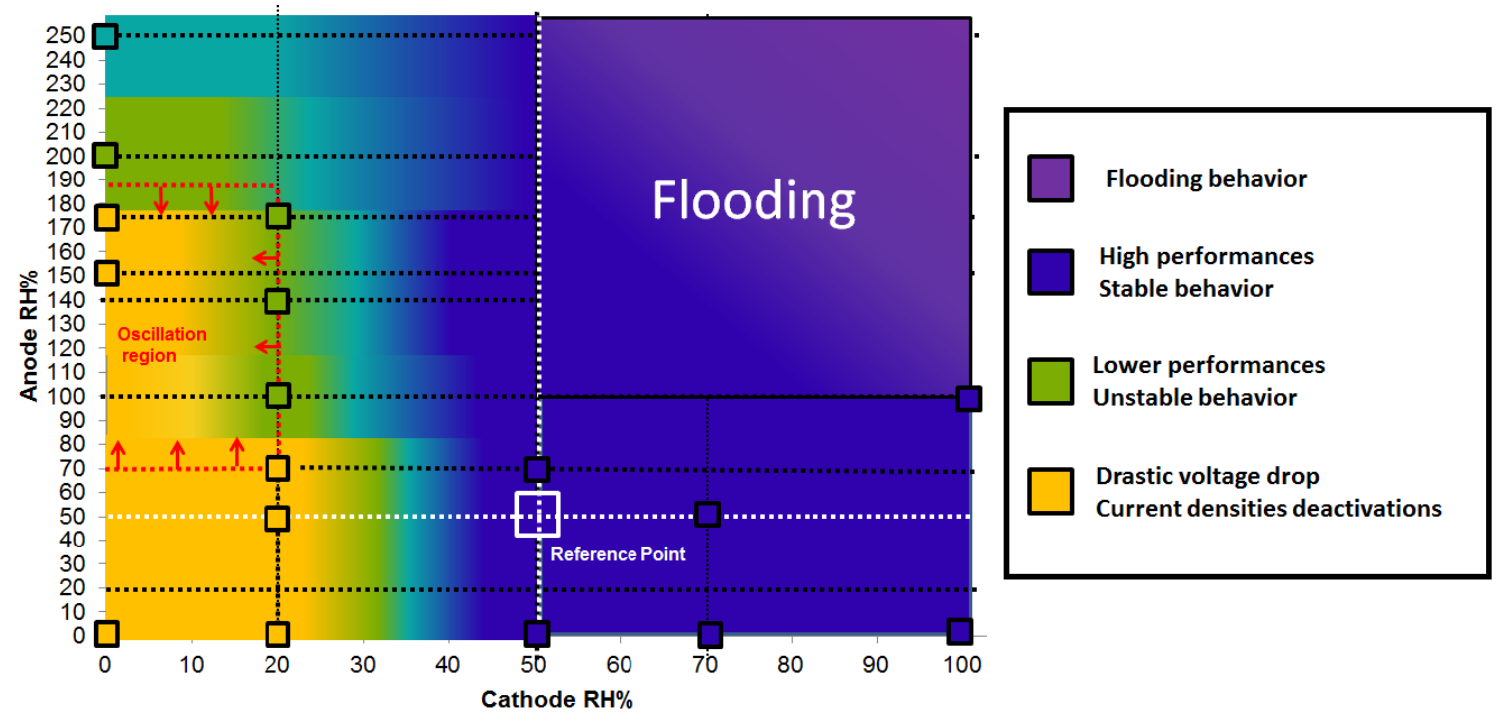

Figure 13. Relation between RH and cell stability. Squares represent RH conditions adopted during different experiments.

The long operation under dry cathode air supply can be associated to heterogeneous and irreversible degradation process, although no large variations in catalyst active area has been measured. With spectroscopic ex-situ investigations, the irreversible deactivation in certain areas of the cell, which was observed with in-situ current density measurements, could be correlated to a strong degradation and demixing of the PTFEcarbon moiety in the MPL. Due to this degradation, the delicate hydrophobicity balance is disturbed, and the local cell deactivation can be attributed to water management issues.

\section{Acknowledgments}

This work has been partially supported by the European Union's Seventh Framework Programme (FP7/2007-20013) for Fuel Cell and Hydrogen Joint Technology Initiative under grants no 303446 and 325239, and by Project ENE2011-24574 of the Spanish 
Ministerio de Economía y Competitividad. Authors would also like to thank H. Sander at DLR and P. García-Ibarra at the Dept. Fisica Matematica y de Fluidos (UNED) for helpful suggestions and discussions.

\section{References}

1. F. N. Buchi and S. Srinivasan, J. Electrochem. Soc., 144, 2767 (1997).

2. J. R. Atkins, S. C. Savett and S. E. Creager, J. Power Sources, 128, 201 (2004).

3. H. K. Hsuen and K. M. Yin, Electrochim. Acta, 62, 447 (2012).

4. D. G. Sanchez and P. L. Garcia-Ybarra, Int. J. Hydrogen Energy, 37, 7279 (2012).

5. S. Vengatesan, H. J. Kim, E. A. Cho, S. U. Jeong, H. Y. Ha, I. H. Oh, S. A. Hong and T. H. Lim, J. Power Sources, 156, 294 (2006).

6. H. T. Kim, K. Y. Song, T. V. Reshetenko, S. I. Han, T. Y. Kim, S. Y. Cho, M. K. Min, G. S. Chai and S. C. Shin, J. Power Sources, 193, 515 (2009).

7. Y. Lee, B. Kim and Y. Kim, Int. J. Hydrogen Energy, 34, 7768 (2009).

8. T. Colinart, A. Chenu, S. Didierjean, O. Lottin and S. Besse, J. Power Sources, 190, 230 (2009).

9. E. Gulzow, M. Schulze, N. Wagner, T. Kaz, R. Reissner, G. Steinhilber and A. Schneider, J. Power Sources, 86, 352 (2000).

10. M. Schulze, E. Gulzow, S. Schonbauer, T. Knori, and R. Reissner, J. Power Sources, 173, 19 (2007).

11. J. Benziger, E. Chia, J. F. Moxley and I. G. Kevrekidis, Chem. Eng. Sci., 60, 1743 (2005).

12. D. G. Sanchez, D. G. Diaz, R. Hiesgen, I. Wehl and K. A. Friedrich, J. Electroanal. Chem., 649, 219 (2010).

13. D. G. Sanchez, A. Ortiz and K. A. Friedrich, J. Electrochem Soc., 160, F636 (2013).

14. I. Nazarov and K. Promislow, Chem. Eng. Sci., 61, 3198 (2006).

15. P. Berg, K. Promislow, J. St. Pierre, J. Stumper and B. Wetton, J. Electrochem. Soc., 151, A341 (2004).

16. T. E. Springer, T. A. Zawodzinski and S. Gottersfeld, J. Electrochem. Soc., 138, 2334 (1991).

17. K. Jiao and X. Li, Progr. Energ. Combust., 37, 221 (2011).

18. R. O'Hare, S. W. Cha, W. G. Colella and F. B. Prinz, Fuel cell fundamentals, John Wiley \& Sons, (2009).

19. K. Siegbahn, J. Electron Spectr. Relat. Phenom., 5,3 (1974).

20. S. Zhang, X.-Z. Yuan, J. Ng Cheng Hin, H. Wang, K. A. Friedrich and M. Schulze, J. Power Sources, 194, 588 (2009).

21. M. Schulze and A. Haug, in Handbook of PEM Fuel Cell Durability Vol. 2. PEM Fuel Cell Diagnostic Tools, H. Wang, X.-Z. Yuan, H. Li, Editors, p. 381, Taylor \& Francis Group, LLC, CRC Press (2011).

22. I. Biswas, P. Gazdzicki and M. Schulze, ECS Transactions, 58(1), 1429 (2013).

23. P. J. Ferreira, G. J. la O', Y. Shao-Horn, R. Makharia and H. A. Gasteiger, J. Electrochem. Soc., 152(11), A2256 (2005).

24. M. S. Wilson, F. H. Garcia, K. E. Sickafus and S. Gottesfeld, J. Electrochem. Soc., 140, 2872 (1993).

25. M. Schulze, N. Wagner, T. Kaz and K. A. Friedrich, Electrochim. Acta, 52, 2328, (2007). 